\title{
The Design of Main Transmission System of the CK1440A Series Numerically-Controlled Machine Tool
}

\author{
DING Jiajun \\ School of Mechanical Engineering \\ Nanjing Institute of Industry Technology \\ Nanjing, Jiangsu, China. \\ dingjj@niit.edu.cn
}

\author{
ZHANG Zhiying \\ Nanjing CNC Machine Tool Co. Ltd. \\ Nanjing, Jiangsu, China. \\ zhangzhiying@sina.com
}

\begin{abstract}
In order improve the performance of the CK1440 type and TND360 type numerically-controlled machine tools, based on the CK1440 type numerically-controlled machine tool, the CK1440A type numerically-controlled machine tool was designed. In order to extend the range of the application of the CK1440A type numerically controlled machine tool, it is necessary to simplify the design of the spindle box. In the paper, according to all kinds of typical processing object, the main transmission system of the CK1440A type numerically-controlled machine tool is improved by modular design, various Spindle speed and the range of constant power drive speed is designed. The results show the range of application of the CK1440A type numerically-controlled machine tool is extended remarkably.
\end{abstract}

Keywords-Numerically-controlled machine tool; design of main transmission system; spindle box

\section{INTRODUCTION}

The TND360 type numerically-controlled (Abbreviation NC) machine tool was manufactured in China by introducing from Germany's advanced technology. The TND360 type NC machine tools in China enjoy wide popularity mainly because of high rigidity, high cutting force, excellent processing efficiency, good processing size consistency of the German machine tool ${ }^{[1]}$.

A series of NC machine tools was designed after the TND360 type NC machine tool was localized. The CK1440A type NC machine tool is one of the series of NC machine tools, and is a middle-grade NC machine tool, the maximum processing diameter of the CK1440A type NC machine tool is $400 \mathrm{~mm}$.

The structure of the TND360 type NC machine tool is contradictive against the modern design trend of NC machine tool, simplifying design of spindle box, reducing the manufacturing difficulty, and improving machine reliability is the trend of modern NC machine tool. The NC machine tools that the maximum processing diameter is $400 \mathrm{~mm}$ have maximum market share, about 40\%, if the CK1440A type NC machine tools can change the maximum processing diameter from $400 \mathrm{~mm}$ to $360 \mathrm{~mm}$ and $500 \mathrm{~mm}$, the CK1440A type NC machine tool can have 50\% market share.
The enterprises give expectation on the CK1440A type NC machine tool. By improve the performance of CK1440A type NC machine tool based on TND360 type, the enterprises hope to win the Initiative in the field of NC machine tool that the maximum processing diameter is $400 \mathrm{~mm}$. The volume of automobile production, motor production, military products and Hydraulic and pneumatic products is large at home, the enterprises usually purchase the NC machine tools for processing some key machine parts, the targeted purchase results in fierce price petition. For specific users, personalized solutions in NC machine tools can achieve the best economic benefits.

For CK1440A series NC machine tools, the maximum processing diameter is $360 \mathrm{~mm}$ can be treat as light load module, and the maximum processing diameter is $500 \mathrm{~mm}$ can be treat as heavy load module in the overall scheme, then the enterprise can improve efficiency, and reduce costs under expected sales target.

In order to improve the maximum processing diameter from $400 \mathrm{~mm}$ to $600 \mathrm{~mm}$ and $1500 \mathrm{~mm}$, and can be compatible with the TND360 type NC machine tool, it is necessary to design the CK1440A series NC machine tool. The key to resolute the abovementioned problems is modular design on the main transmission system of the CK1440A series NC machine tool.

\section{TECHNICAL SCHEME}

For the design of the CK1440A series NC machine tool, the design of the main transmission system must be included within a series of solutions, and take the development of the AC main motor into account. The design of the main transmission system determined the various component modules through the analysis of typical parts and typical industry, in the course of design of the main transmission system, the main components is unchanged, the series of solutions can meet the users' demand economically by changing the diameter of the belt wheel and configuring the different AC motors.

In order to select easily the NC machine tool for the users with different processing diameter and different processing 
load, the spindle is designed following A2-5, A2-6, and A2-8 spindle standard. In the design of the CK1440A series NC machine tool, the constant power range of the AC spindle motor of the CK1440A type NC machine tool is 15003000rpm / 1500-6000rpm/1500-8000rpm, and the power range of AC main motor is $15 \mathrm{KW}-22 \mathrm{KW}$, and spindle speed range must be compatible with TND360 type NC machine tool and the $\mathrm{NC}$ machine tool that the processing diameter is $400 \mathrm{~mm}$, the processing length of the CK1440A series NC machine tools is $600 \mathrm{~mm}, 1000 \mathrm{~mm}, 1500 \mathrm{~mm}$. For the design of the CK1440A type NC machine tool, there are 9-27 solutions, all of that can promote the market share of the CK1440A type NC machine tools ${ }^{[2,3]}$.

\section{Determine The SPINDle SPEed RANGE.}

According to the design specifications of NC machine tool, by defining the maximum processing diameter, the minimum processing diameter, the maximum cutting speed and the minimum cutting speed of the NC machine tool that the processing diameter is $360 \mathrm{~mm}$ and $400 \mathrm{~mm}$, the spindle speed range is calculated.

By defining Maximum cutting parameters of NC machine tools, the maximum power of the main motor is calculated, the maximum cutting torque and the constant power range of the NC machine tool is calculated, and the pulley diameter, the number of narrow V-belt is determined. The spindle box of the CK1440A type NC machine tool must be compatible with the others.

\section{A. Processing Diameter of NC Machine Tool is $360 \mathrm{mmr} / \mathrm{s}$}

According as the design specifications of NC machine tool, the maximum processing diameter of the $\mathrm{NC}$ machine tool is $d_{\max }=k D$. For the Horizontal lathe, the parameter $k=0.5$, the maximum processing diameter of the TND360 type NC machine tool is $180 \mathrm{~mm}$, i.e. $D=180 \mathrm{~mm}$, then $d_{\max }=k D=0.5 \times 180=90 \mathrm{~mm}$, the ratio of the maximum processing diameter and the minimum processing diameter is $R_{d}=d_{\min } / d_{\max }$, for the Horizontal lathe, the parameter $R_{d}=0.25$, then the minimum processing diameter $d_{\min }=22.5 \mathrm{~mm}$. The maximum processing velocity of the NC machine tool is define as $V_{\max }=200 \mathrm{~m} / \mathrm{min}$ (for fine finishing cylindrical, steel, carbide cutting tools), and the minimum processing velocity of the NC machine tool is defined as $V_{\min }=16 \mathrm{~m} / \mathrm{min}$ (for roughing cylindrical, cast iron, carbide cutting tools), then the minimum spindle speed is :

$$
n_{\text {min }}=1000 \times V_{\text {min }} /\left(\pi \times d_{\text {max }}\right)=56.6(\mathrm{rpm})
$$

and the maximum spindle speed is:

$$
n_{\max }=1000 \times V_{\max } /\left(\pi \times d_{\min }\right)=2830(\mathrm{rpm})
$$

For the Carbide coated tool and fine finishing non-ferrous metal, the maximum spindle speed should be increased $20 \%$ $25 \%$, inferring to the maximum spindle speed of the TND360 type NC machine tool, the maximum spindle speed should be determined as $n_{\max }=3500 \mathrm{rpm}$. For the limit roughing diameter of cast iron and gear ratio of spindle of full function NC machine tool, the minimum spindle speed should be determined as $n_{\min }=35 \mathrm{rpm}^{[4]}$.

\section{B. Processing Diameter of NC Machine Tool is $400 \mathrm{mmr} / \mathrm{s}$}

According as the design specifications of NC machine tool, the maximum processing diameter of the $\mathrm{NC}$ machine tool is $d_{\max }=140 \mathrm{~mm}$, the minimum processing diameter of the NC machine tool is $d_{\min }=35 \mathrm{~mm}$. The maximum processing velocity of the NC machine tool is define as $V_{\max }=200 \mathrm{~m} / \mathrm{min}$, and the minimum processing velocity of the NC machine tool is defined as $V_{\min }=16 \mathrm{~m} / \mathrm{min}$, then the minimum spindle speed is $n_{\text {min }}=1000 V_{\text {min }} /\left(\pi d_{\text {max }}\right)=36.39 \mathrm{rpm}$, and the maximum spindle speed is $n_{\max }=1819 \mathrm{rpm}$. For the Carbide coated tool and fine finishing non-ferrous metal, the maximum spindle speed should be increased 50\%-65\%, then the maximum spindle speed should be determined as $n_{\max }=3000 \mathrm{rpm}$. For the limit roughing diameter of cast iron and gear ratio of spindle of full function NC machine tool, then the minimum spindle speed should be determined as $n_{\text {min }}=35 \mathrm{rpm}^{[5]}$.

\section{Research at Home and Abroad}

For the NC machine tool that the processing diameter is $400 \mathrm{~mm}$, the maximum spindle speed is $n_{\max }=3000 \mathrm{rpm}$. For the NC machine tool that the processing diameter is $360 \mathrm{~mm}$, the maximum spindle speed is $n_{\max }=3500 \mathrm{rpm}$.

\section{Results}

For the CK1440A series NC machine tool that the speed range is 35-3500rpm, they fit the users who use the TND360 type NC machine tool previously. For the CK1440A type NC machine tool series that the speed range is 35-3000rpm, they fit the users who use previously the NC machine tool that the processing diameter is $400 \mathrm{~mm}$.

\section{Determine the Power of the Main Motor.}

According as the design specifications of NC machine tool, $F_{Z}=9.81 C_{F_{Z}} \alpha_{p} X_{F_{Z}} f Y_{F_{Z}} V Z_{F_{Z}} K_{F_{Z}} \quad, \quad P_{E}=P_{m} / \eta$ $P_{m}=F_{z} V / 60000(\mathrm{kw})$. Selecting the cutting parameter, Rough steel and extreme load conditions $\alpha_{p}=10 \mathrm{~mm}, f=0.6 \mathrm{~mm} / \mathrm{rpm}, V=80 \mathrm{~mm} / \mathrm{min}, C_{F_{Z}}=270$, $X_{F_{Z}}=1, Y_{F_{Z}}=-0.75$, and $K_{F_{Z}}=K_{m F_{Z}} K_{r F_{Z}} K_{k F_{Z}} K_{\lambda F_{Z}}$, where the 
parameter $K_{m F_{z}}=\left(\sigma_{b} / 0.67\right) \times n_{F}$. For hard alloy, the parameter $n_{F}=0.75$, now, we select No. 45 steel, the hardness of No. 45 steel is C42, the parameter $\quad \sigma_{b}=1176.8 \mathrm{~N} / \mathrm{mm}^{2}=1.1768 \mathrm{GPa}$, then $K_{m F_{Z}}=1.5846$. We select the tool geometrical rake $\gamma_{0}=10^{\circ}$, tool orthogonal rake $K_{r}=45^{\circ}$, and tool cutting edge inclination angle $\lambda s=5^{\circ}$, then the parameter $K_{F_{Z}}=1.5846$, the parameter $F_{Z}=14827(\mathrm{~N})$, $P_{m}=19.77(\mathrm{kw}), \quad P_{E}=P_{m} / \eta=20.81(\mathrm{kw})$. According to research at home and abroad, the power of the DC spindle motor of the TND360 type NC machine tool is $27 \mathrm{kw}$, and the power of the AC spindle motor of the TND360 type NC machine tool is $22 \mathrm{kw}$, the power of spindle motor of the NC machine tool that the processing diameter is $400 \mathrm{~mm}$ is $15 \mathrm{kw}$, in Taiwan, Korea, and Japan, the power of spindle motor is about 15kw, in German, USA, and UK, the power of spindle motor is about $18-22 \mathrm{kw}^{[6]}$.

According to the abovementioned analysis, considering the continuous improvement of performance of AC spindle motor, the power of spindle motor is determined as $15-22 \mathrm{kw}$, Fig. 1 shows that the power of spindle motor varies with the spindle speed.

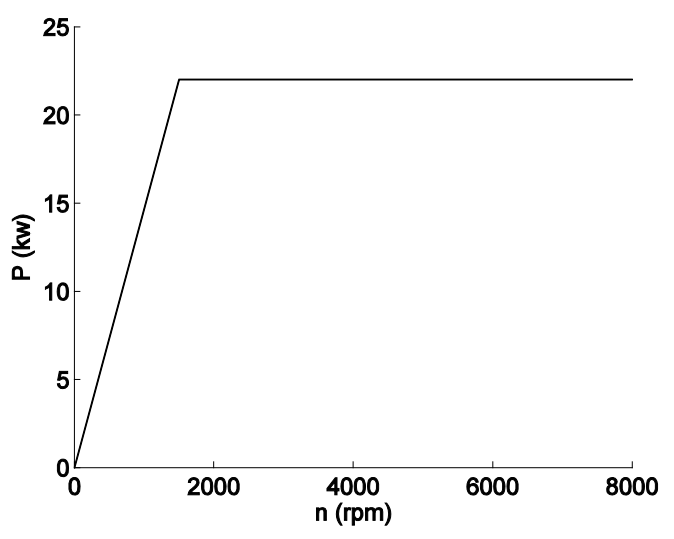

Fig.1. Speed of AC spindle motor

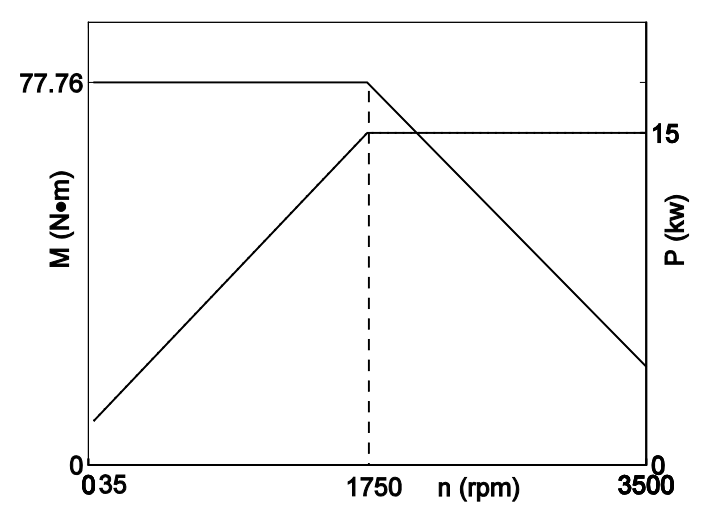

Fig.2.Spindle speed, torque and power under light load

\section{Determine the Calculated SpeEd AND the MAXIMUM CUTTING TORQUE.}

\section{A. Calculated Speed and the Maximum Cutting Torque under Light Cutting Load}

The maximum spindle speed is 3500rpm, the power of AC spindle motor is $15 \mathrm{kw}$, the range of spindle speed under constant power is 1500 -3000rpm. The main transmission ratio is1.17, and the calculated speed is $n=1750 \mathrm{rpm}$. The maximum cutting torque of the NC machine tool is:

$$
M_{\max }=9550 \times \eta / n=77.76(N \cdot m) .
$$

Fig.2 shows the calculated speed and the maximum cutting torque under light cutting load.

\section{B. Calculated Speed and the Maximum Cutting Torque under Medium Cutting Load}

The maximum spindle speed is 3000rpm, the power of AC spindle motor is $18 \mathrm{kw}$, and the range of spindle speed under constant power is $1500-6000 \mathrm{rpm}$. The main transmission ratio is 2 , and the calculated speed is $n=750 \mathrm{rpm}$. The maximum cutting torque of the NC machine tool is:

$$
M_{\max }=9550 \times \eta / n=217.74(N \cdot m)
$$

Fig.3 shows the calculated speed and the maximum cutting torque under medium cutting load.

\section{Calculated Speed and the Maximum Cutting Torque under heavy Cutting Load}

The maximum spindle speed is 3000rpm, the power of AC spindle motor is $22 \mathrm{kw}$, and the range of spindle speed under constant power is $1500-8000 \mathrm{rpm}$. The main transmission ratio is 2.667, and the calculated speed is $n=562 \mathrm{rpm}$. The maximum cutting torque of the NC machine tool is:

$$
M_{\max }=9550 \times \eta / n=355.15(N \cdot m) .
$$

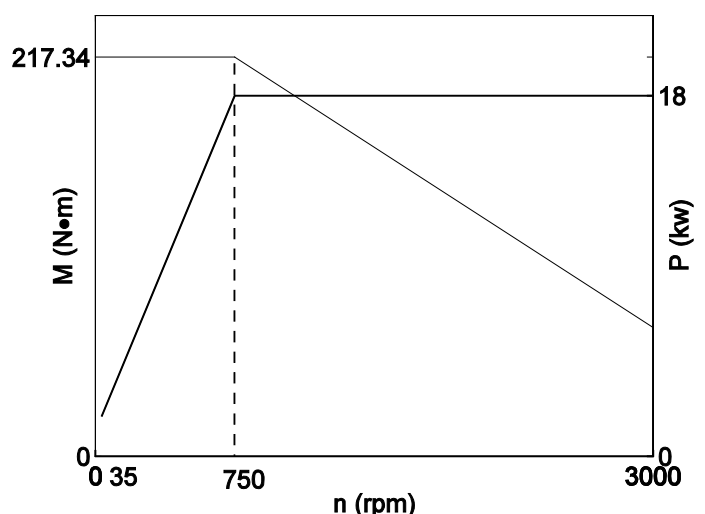

Fig.3. Spindle speed, torque and power under medium load 


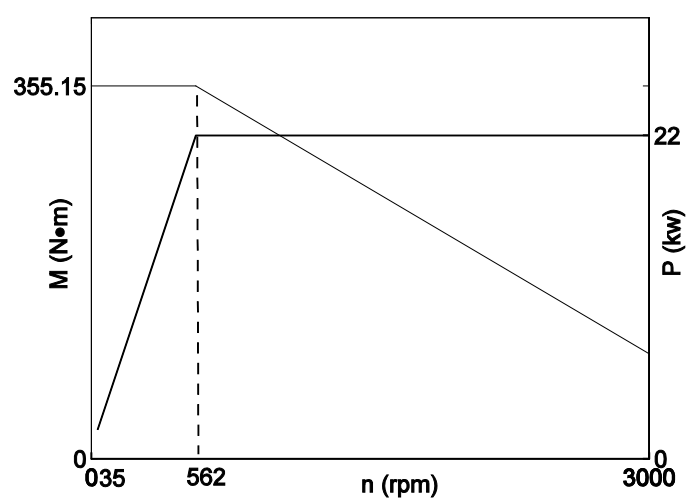

Fig.4. Spindle speed, torque and power under heavy load

Fig. 4 shows the calculated speed and the maximum cutting torque under heavy cutting load.

\section{Determine The Diameter of Pulley WheEl AND THE NUMBER OF NARROW V-BELT}

The small pulley is installed on the AC spindle motor, and the big pulley is installed on spindle, the diameter of pulley is related with the diameters of the axis of spindle motor and the axis of spindle.

Considering the light load, medium load and heavy load respectively corresponding with $A_{2}-5, A_{2}-6$, and $A_{2}-8$ series spindle, we select the SPZ type narrow V-belt. The minimum reference diameter of pulley is $d_{1}=71 \mathrm{~mm}$.

Considering the structure of a series of spindle bearings and the spindle, we determine the corresponding parameters under different cutting load.

\section{A. Determine the Parameters under Light Cutting Load}

The diameter of spindle pulley is $d_{2}=112 \mathrm{~mm}$ (according to the $A_{2}-5$ spindle head size, the diameter of front bearings and rear bearings of spindle is determined. According to structure of spindle and diameter of pulley, the calculated diameter of spindle pulley is determined). The ratio of spindle motor speed and spindle speed is $i=3000 / 3500=0.8571$, and the diameter of pulley of spindle motor is $d_{1}=d_{2} / i=130.67$, we select $d_{1}=132 \mathrm{~mm}$. The limit velocity of belt is $V=\pi \times d_{1} n / 6000=20.724(\mathrm{~m} / \mathrm{s})$, and the calculated power is $P_{C}=16.5(k w)$. The number of narrow $\mathrm{V}$ belt is $z=P_{C} \times K_{a} \times K_{L} /\left(P_{0}+\Delta P_{0}\right)=2.22$, we select the number of narrow $\mathrm{V}$-belt is 3 .

\section{B. Determine the Parameters under Medium Cutting Load}

The diameter of pulley of spindle motor is $d_{1}=d_{2} / i=90 \mathrm{~mm}$, the ratio of spindle motor speed and spindle speed is $i=6000 / 3000=2$, and the diameter of spindle pulley is $d_{2}=180 \mathrm{~mm}$. The limit velocity of belt is $V=\pi \times d_{1} n / 6000=28.26(\mathrm{~m} / \mathrm{s})$, and the calculated power is $P_{C}=19.8(\mathrm{kw})$. The number of narrow V-belt is $Z=P_{C} \times K_{a} \times K_{L} /\left(P_{0}+\Delta P_{0}\right)=4.06 \approx 4$.

\section{Determine the Parameters under Heavy Cutting Load}

The diameter of pulley of spindle motor is $d_{1}=d_{2} / i=95 \mathrm{~mm}$, the ratio of spindle motor speed and spindle speed is $i=8000 / 3000=2.67$, and the diameter of spindle pulley is $d_{2}=253.65 \mathrm{~mm}$, we determine the diameter of spindle pulley is $250 \mathrm{~mm}$. The limit velocity of belt is $V=\pi \times d_{1} n / 60000=39.77(\mathrm{~m} / \mathrm{s})$, and the calculated power is $P_{C}=24.2(k w)$. The number of narrow V-belt is $Z=P_{C} \times K_{a} \times K_{L} /\left(P_{0}+\Delta P_{0}\right)=4.58 \approx 5$.

\section{CONCLUSIONS}

Based on different cutting load, three main transmission modules are determined. By designing, calculating and analyzing, we select the type of narrow v-belt, spindle motor and diameter of spindle pulley. We calculate the limit speed of narrow v-belt and determine the number of narrow v-belts and the main transmission program.

The CK1440A series NC machine tools are classified into 27 type NC machine tool according to main drive, spindle head structure, processing length, and cover the range of processing diameter from $300 \mathrm{~mm}$ to $500 \mathrm{~mm}$. Based on the users who using the TND360 type NC machine tool, the CK1440A series NC machine tool further expand the market, and create better economic efficiency for enterprise.

\section{References}

[1] W. D. Du, "Design of main transmission system of the JIFCNC-B numerically-control machine tool,” Technology and Living, vol. 17, pp. 192-192, 2011.

[2] J. Kong, L. Tan, "Dynamic optimization design of spindle drive system of numerically-control machine tool,” Mechanical Transmission, vol. 7, pp. 59-61, 2012.

[3] Y. Q. Ma, “The design of main transmission system of the CK6163 Type numerically-controlled machine tool,” Silicon Valley, no. 17, pp. 17-18, 2014.

[4] T. F. Ren, "Research on new ideas of improve precision CNC machining,” Hei Long Jiang Science, vol.6, no. 1, pp. 43-45, 2015.

[5] J. Qiu, R. P. Ge, X. T. Zhang, "Cutting load test method of machining centre and its experimental test," Manufacturing Technology and Machine tool, no.1, pp. 189-192, 2015.

[6] S. H. Gao, G. Meng, "Advances in research on dynamic characteristics of machine tool spindle,” Journal of Vibration and Shock, vol. 26, no. 6, pp. 103-109,2007. 